\title{
Chronic peripheral neuropathy in workers with previous exposure to carbon disulphide
}

\author{
G CORSI, ${ }^{1}$ P MAESTRELLI, ${ }^{1}$ G PICOTTI, ${ }^{1}$ S MANZONI, ${ }^{2}$ AND P NEGRIN ${ }^{2}$ \\ From the Occupational Medicine Institute' and the Laboratory of Electromyography, ${ }^{2}$ Department of \\ Neurological and Mental Diseases, University of Padua, Padua, Italy
}

ABSTRACT Two groups of viscose rayon production workers were examined 10 years after discontinuation of exposure to $\mathrm{CS}_{2}$. Group A comprised 20 subjects exposed to high $\mathrm{CS}_{2}$ concentrations and group B 13 subjects with lower exposure. Clinical findings and the measurements of nerve conduction velocity of the slow fibres in the peripheral nerves were evaluated. Twelve subjects had both clinical and electromyographic evidence of neuropathy and 10 showed a diminution in motor conduction velocity. A relationship between the degrees of exposure to $\mathrm{CS}_{2}$ and prevalence of polyneuropathy was found. On re-examining 12 subjects with neuropathy who had been examined four years before no significant electromyographic improvement was observed. These findings are consistent with a permanent axonal neuropathy caused by carbon disulphide.

Peripheral neuropathy due to carbon disulphide poisoning has been reported by many investigators, ${ }^{1-11}$ all of whom agree that electromyography is a sensitive method for its early diagnosis. In particular, there is a clear relation between exposure to $\mathrm{CS}_{2}$ and alterations in the maximal motor conduction velocity (MCV), the conduction velocity of the slower motor fibres (SFCV), and the distal latency. There are, however, few data on the electrophysiological changes that occur after cessation of exposure. Manu et al $^{3}$ observed an improvement in the electromyography pattern of subjects after a reduction in or the cessation of exposure to $\mathrm{CS}_{2}$, and Giglioli et $a l^{10}$ found incomplete signs of neurophysiological recovery in subjects whose exposure to $\mathrm{CS}_{2}$ had ceased eight years before.

The aim of this work, therefore, was to study the prevalence of $\mathrm{CS}_{2}$ neuropathy in workers 10 years after exposure had ceased.

\section{Subjects and methods}

Thirty three viscose rayon plant workers were selected on the basis of the following criteria:

(1) They had been exposed to $\mathrm{CS}_{2}$ for more than eight years;

(2) They had stopped working in the plant 10 or

Received 24 May 1982

Accepted 23 June 1982 more years before the present study was undertaken; and

(3) They had no concomitant factors that could cause peripheral neuropathy, such as alcohol consumption of more than $100 \mathrm{~g} /$ day, diabetes, dietary deficiencies, serious liver diseases, or cancer.

The patients were divided into two groups based on the degree of $\mathrm{CS}_{2}$ exposure. Group A comprised 20 subjects who had been employed on the sulphidation and xanthation process, or in the fibre spinning and rayon washing departments. The 13 subjects in group $B$ had not been continuously exposed to $\mathrm{CS}_{2}$ having been either maintenance staff or employed in other jobs.

All the patients were submitted to a neurological examination and to electromyography (EMG), the latter performed on the abductor digiti $\mathrm{V}$ and extensor digitorum brevis, using a Medelec MS6 apparatus and coaxial needle electrodes. The MCV and the SFCV of the ulnar and peroneal nerves were thus determined. Twelve subjects with neuropathy who had previously been examined (on average four years before) using the same apparatus and method were also studied to determine whether any improvement could be noted.

Carbon disulphide concentrations in the sulphidation, spinning, and washing departments of the plant, measured in $1951,{ }^{12}$ were six to seven times greater than the TLV of $30 \mathrm{mg} / \mathrm{ml}^{13}$ and continuously exceeded this value later. 
Table 1 Results of clinical and EMG investigations and relation between diagnosis of neuropathy and age

\begin{tabular}{lll}
\hline Diagnosis & $\begin{array}{l}\text { No of } \\
\text { subjects }\end{array}$ & Age (years) \\
\hline Definite neuropathy & 12 & $65 \cdot 8 \pm 7 \cdot 0$ \\
Latent neuropathy & 10 & $61 \cdot 4 \pm 6 \cdot 6$ \\
Normal findings & 11 & $64 \cdot 1 \pm 10 \cdot 7$ \\
\hline
\end{tabular}

\section{Results}

Table 1 shows the results of clinical and EMG investigations, and the relation between diagnosis of neuropathy and age. Twelve subjects had definite neuropathy-that is, objective signs of peripheral alterations in the nervous system (distal sensory loss, altered tendon reflexes, diminished muscle power, or muscle atrophy) and reduction of motor conduction velocities. Eleven had latent neuropathy defined as a reduction of motor conduction velocities without objective signs. In 10 the findings were normal. No relation was found between age and the diagnosis of neuropathy. In fig 1 individual values MCV and SFCV of the peroneal nerve in groups A and B are reported.

The prevalence of neuropathy in groups $\mathbf{A}$ and $\mathbf{B}$ is shown in table 2: $95 \%$ of the subjects with the highest exposure have definite or latent neuropathy compared with $23 \%$ of subjects with discontinuous exposure. No difference between the two groups was found regarding age and years of exposure.

Figure 2 shows the changes in the peroneal nerve SFCV in the 12 subjects examined six (first control) and 10 (second control) years after discontinuation of exposure to $\mathrm{CS}_{2}$. An improvement was found in two, one patient showed a reduction in SFCV, and no changes were observed in the remaining nine.

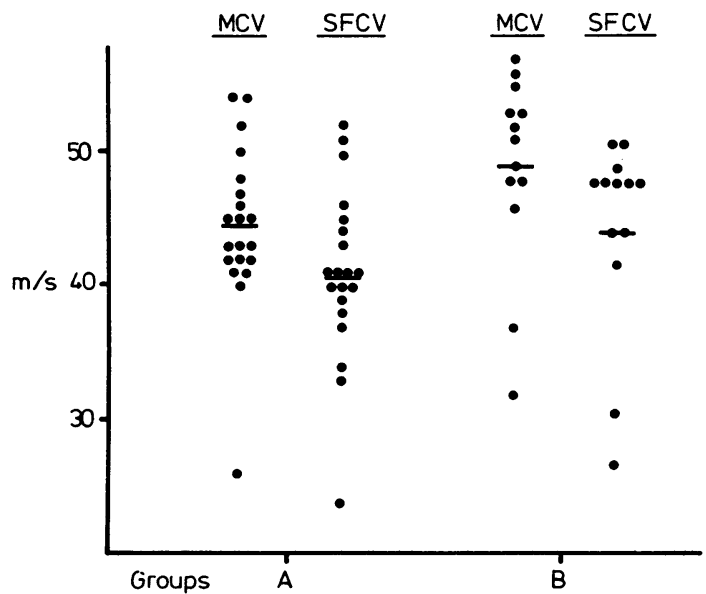

Fig 1 Individual MCV and SFCV values in peroneal nerve of groups $A$ and $B$. Horizontal bars represent mean value.

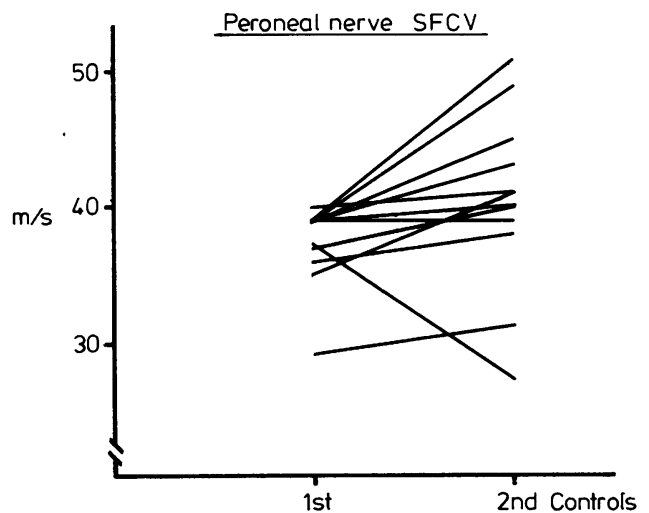

Fig 2 Changes in peroneal nerve SFCV in 12 subjects examined six (first control) and 10 (second control) years after discontinuation of exposure to $\mathrm{CS}_{2}$.

\section{Discussion}

A high prevalence of neuropathy $(67 \%)$ was found in this group of $\mathrm{CS}_{2}$ workers, although it must be borne in mind that the men examined had had a long exposure and that SFCV is a more sensitive measure of nerve damage than MCV alone. ${ }^{610}$ Moreover, five of the 11 subjects with "normal" findings had minimal EMG alterations, such as a lengthening of distal latency, but we thought these signs insufficient to warrant a diagnosis of latent peripheral neuropathy.

In the neuropathic patients the reduction of motor conduction velocity was generally not severe (only five cases had SFCV of less than $35 \mathrm{~m} / \mathrm{sec}$ ) and was more frequent in the longer nerves (in half of the subjects the neuropathy was limited to the peroneal nerve alone and in four cases to the ulnar nerve).

As table 2 shows, the prevalence of neuropathy is related to the intensity of exposure to $\mathrm{CS}_{2}$, whereas age and duration of exposure are not. Only one patient in group A had normal EMG findings, but he had shown signs of a latent polyneuritis four years previously (six years after cessation of toxic exposure). This patient had had milder exposure than the others in group A because he had worked in the fibre washing department only from 1962 to 1971 , when efforts had been made to lower the $\mathrm{CS}_{2}$ concentrations at the workplace.

In group $B$ one of the neuropathic patients

Table 2 Prevalence of neuropathy in Groups $A$ and $B$

\begin{tabular}{llllll}
\hline & $\begin{array}{l}\text { No of } \\
\text { subjects }\end{array}$ & $\begin{array}{l}\text { Age } \\
\text { (years) }\end{array}$ & $\begin{array}{l}\text { Exposure } \\
\text { (years) }\end{array}$ & \multicolumn{2}{c}{$\begin{array}{l}\text { Neuropathy } \\
\text { No }\end{array}$} \\
\hline Group A & 20 & $63 \cdot 0 \pm 7 \cdot 8$ & $22 \cdot 0 \pm 9.5$ & 19 & 95 \\
Group B & 13 & $62.8 \pm 8 \cdot 1$ & $25 \cdot 5 \pm 9 \cdot 2$ & 3 & 23 \\
\hline
\end{tabular}


showed severe EMG alterations (pronounced loss of motor unit), although he had had only slight and irregular exposure to $\mathrm{CS}_{2}$; the diagnosis of neuropathy as a consequence of exposure to $\mathrm{CS}_{2}$ in this case is thus questionable.

In conclusion, a high frequency of toxic peripheral neuropathy was found in subjects who had been exposed to the highest levels of $\mathrm{CS}_{2} 10$ years previously. This disease was not severe but was extremely persistent. Moreover, as no change was observed between the re-examinations six and 10 years after cessation of toxic exposure, the alterations may be considered permanent. These findings are consistent with an axonal neuropathy as studies in animals have shown. ${ }^{14-16}$

\section{References}

${ }^{1}$ Lukas E. Leitgeschwindigkeit peripherer Nerven bei Schwefelkohlenstoff ausgesetsten Personen. Internationale Zeitschrift für Klinische Pharmakologie Therapie und Toxicologie 1969;4:354-8.

${ }^{2}$ Lukas E. To the problem of the so called subclinical forms of polyneuropathies. In: Plestina R, ed. Abstracts of XIX international congress on occupational health, Dubrovnik 25-30 September 1978. Zagreb: Institute for Medical Research and Occupational Health, 1978:482.

${ }^{3}$ Manu P, Lilis R, Lancranjan J, Jonescu S, Vasilescu J. The value of electromyographic changes in the early diagnosis of carbon disulphide peripheral neuropathy. Med Lav 1970;61:102-8.

${ }^{4}$ Lilis R. Behavioral effects of occupational $\mathrm{CS}_{2}$ exposure. Cincinnati, Ohio: US Department of Health, Education and Welfare, National Institute for Occupational Safety and Health 1973:51-9.

s Seppalainen AM, Tolonen M, Karli P, Hanninen H, Hernberg S.
Neurophysiological findings in chronic $\mathrm{CS}_{2}$ poisoning. A descriptive study. Work Environment Health 1972;9:71-5.

- Seppalainen AM. Neurophysiological findings in CS 2 exposure. Chronic $\mathrm{CS}_{2}$ poisoning. Cincinnati, Ohio: US Department of Health, Education and Welfare, National Institute for Occupational Safety and Health, 1973:64-72.

' Seppalainen AM, Tolonen M. Neurotoxicity of long-term exposure to $\mathrm{CS}_{2}$ in the viscose rayon industry: a neurophysiological study. Work Environment Health 1974;11:145-53.

${ }^{8}$ Vasilescu C. Sensory and motor conduction in chronic $\mathrm{CS}_{2}$ poisoning. European Neurology 1976;14:447-57.

- Graovac-Leposavic LJ, Banicevic R, Dzelajalija S, Delic V, Dordevic V. Study on motor nerves conductivity, peripheral circulation and lipid metabolism in workers exposed to $\mathrm{CS}_{2}$. In: Plestina R, ed. Abstracts of XIX international congress on occupational health, Dubrovnik 25-30 September 1978. Zagreb: Institute for Medical Research and Occupational Health, 1978:474.

${ }^{10}$ Giglioli R, Bulgheroni C, Bertazzi PA, et al. Study of neurological and neurophysiological impairment in carbon disulphide workers. Med Lav 1978;69:130-43.

"Arrigo A, Moglia A, Sandrini G, Kokodoko A. EMG findings in $\mathrm{CS}_{2}$ polyneuropathy. In: Cavalleri A, ed. Abstracts of $V$ international symposium on occupational health in the production of artificial fibres. Belgirate, Italy, 16-20 September 1980. Permanent Commission and International Association on Occupational Health, 1980:31.

${ }_{12}$ Nunziante-Cesaro A, Sipala E, Zunini E. Sul solfocarbonismo. Folia medica 1952;35:661-716.

${ }^{13}$ American Conference of Governmental Industrial Hygienists. Threshold limit values of airborne contaminants and physical agents with intended changes. Cincinnati, Ohio: ACGIH, 1980.

${ }_{14}$ Juntunen J, Linnoila I, Haltia M. Histochemical electron microscopic observation on the myoneural junctions of rats with carbon disulphide induced polyneuropathy. Scand $J$ Work Environ Health 1977;3:36-42.

is Knobloch K, Stetkiewicz J, Wronska-Nofer T. Conduction velocity in the peripheral nerves of rats with chronic $\mathrm{CS}_{2}$ neuropathy. $\mathrm{Br} J$ Ind Med 1979;36:148-52.

${ }^{16}$ Maroni M, Colombi A, Rota E, et al. Biochemical and morphological investigation on nervous tissue of rats inhaling $\mathrm{CS}_{2}$. Med Lav 1979;70:443-51. 